\title{
Immobilization of pentachlorophenol in soil using carbonaceous material amendments
}

\author{
Bei Wen ${ }^{\mathrm{a}, *}$, Rui-juan $\mathrm{Li}^{\mathrm{a}}$, Shuzhen Zhang ${ }^{\mathrm{a}}$, Xiao-quan Shan ${ }^{\mathrm{a}, *}$, Jing Fang ${ }^{\mathrm{a}}$, Ke Xiao ${ }^{\mathrm{a}}$, Shahamat U. Khan ${ }^{\mathrm{b}}$

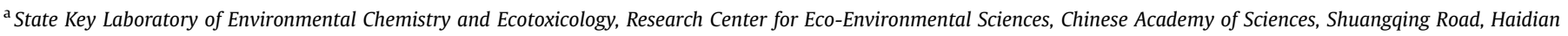 \\ District, Beijing 100085, China \\ ${ }^{\mathrm{b}}$ Department of Chemistry and Biochemistry, MSN 3E2, George Mason University, 4400 University Drive, Fairfax, VA 22030-4444, USA
}

Carbonaceous material amendment was a potential in situ remediation method for pentachlorophenol contaminated soil.

\section{A R T I C L E I N F O}

\section{Article history:}

Received 18 June 2008

Received in revised form

17 October 2008

Accepted 19 October 2008

\section{Keywords:}

Soil

Pentachlorophenol

Carbonaceous material amendments

Bioavailability

\begin{abstract}
A B S T R A C T
In this study, three pentachlorophenol (PCP) laboratory-spiked and one field-contaminated soil were amended with $2.0 \%$ char, humic acid (HA) and peat, respectively. The amended soils were aged for either 7 or 250 days. After amendment, $\mathrm{CaCl}_{2}$ extractability of PCP was significantly decreased. Desorption kinetics indicated that the proposed amendment could lead to a strong binding and slow desorption of PCP in soils. Amendment with char reduced the bioaccumulation factor (BAF) of PCP most significantly for earthworms (Eisenia fetida) in all soils studied. The results of both physicochemical and biological tests suggested that amendment reduced PCP bioavailability quickly and enduringly, implying that carbonaceous material amendment, especially char amendment, was a potentially attractive in situ remediation method for sequestration of PCP in contaminated soil.
\end{abstract}

(c) 2008 Elsevier Ltd. All rights reserved.

\section{Introduction}

Soil and sediment are regarded as ultimate sink of large number of organic contaminants in terrestrial and aquatic ecosystem (Davies et al., 1999; Skrbic and Durisic-Mladenovic, 2007). Soil remediation technologies emphasize the transformation and detoxification of contaminants. Compared with conventional expensive, invasive, and sometimes ineffective techniques, such as excavation and dredging, in situ treatment strategies are more effective at reducing risk and decreasing expenditures on management. Among various in situ treatments, bioremediation is thought to enable permanent elimination of pollutants at low cost. However, its effectiveness is limited by the appropriate soil conditions for microbial activity, recalcitrance of pollutants to biodegradation, and formation of metabolites which may be more toxic than the parent contaminant (Boopathy, 2000). Moreover, natural organic matters in soil and sediment serve as dominant environmental "compartments" for sorption and accumulation of organic pollutants. The degradation of organic pollutants in soil is affected mainly by soil organic matter (SOM) and clay mineral contents and compositions, which limits the bioavailability of

\footnotetext{
* Corresponding authors. Tel.: +86 10 62849329; fax: +86 1062923563. Shan)
}

organic pollutants to microbes (Hatzinger and Alexander, 1995; Boopathy, 2000).

Based on the above observations, an in situ remediation method to reduce bioavailability of organic pollutants by repartitioning of organic contaminants to carbonaceous sorbents that were mixed with soil to enhance the natural process of contaminant stabilization was proposed by Weber et al. (2006). They developed engineered sorbents from natural organic materials, such as peat, soybean stalk and pine needle under superheated temperature/ pressure conditions, for sorption of polycyclic aromatic hydrocarbons (PAHs) in contaminated soils. Both natural and engineered natural materials significantly decreased the extractability and bioavailability of PAHs from contaminated soil (Tang and Weber, 2006; Weber et al., 2006; Tang et al., 2007). Addition of active carbon to sediments affected desorption of polychlorinated biphenyls (PCBs) and PAHs (Zimmerman et al., 2004). The bioavailability and bioaccumulation of PCBs were reduced remarkably by activated carbon amendment in both laboratory (Millward et al., 2005) and field (Cho et al., 2007) tests. These works demonstrated clearly the effectiveness of amendments for immobilization of hydrophobic organic contaminants in soil/sediment. However, it should be pointed out that the carbonaceous materials were only used to immobilize non-polar hydrophobic organic contaminants in the above noted studies. The effectiveness for stabilization of polar or ionizable organic contaminants such as pentachlorophenol (PCP) has not been addressed. 
Cation surfactant bound bentonite has been proposed for potential application in remediation of contaminated water and soil based on its powerful sorption of polar and ionizable organic contaminants (Chen et al., 2005). However, synthetic surfactants may become an environmental problem because of their biological toxicity (Conte et al., 2005).

The use of PCP and its salt since the 1930s as a biocide and a wood preserving reagent has led to serious soil contamination (Boyd et al., 1989). The objective of this work was to determine the effect of three common organic amendments, char, humic acid (HA), and peat, on the immobilization of PCP in contaminated soils. Serial comparisons were made before and after amendments, including (1) fractionation distribution pattern of PCP in soils; (2) desorption kinetics and (3) bioaccumulation to earthworm (Eisenia fetida). Additionally, the immobilization of PCP in the amended soil as affected by the incubation time was also assessed.

\section{Materials and methods}

\subsection{Chemicals}

Dichloromethane (DCM), methanol, $n$-butanol $(\mathrm{BuOH})$, and n-hexane (Mallinckrodt, USA) were of HPLC grade. Anhydrous potassium carbonate, anhydrous sodium sulphate, dehydrate calcium chloride (Beijing Chemical Reagents Company, China) were of analytical grade. Anhydrous sodium sulphate was heated at $400^{\circ} \mathrm{C}$ for $4 \mathrm{~h}$ in muffle furnace before use to remove organic compounds. Sodium azide (Dongyang Tianyu Chemical Ltd., Zhejiang, China) was of analytical grade.

Reference standards of PCP (AccuStandard Inc., New Haven, USA), internal standard 2,4,6-tribromophenol (TBP, AccuStandard Inc., New Haven, USA) were made in n-hexane, stored in sealed volumetric flasks and preserved at $4{ }^{\circ} \mathrm{C}$. All containers were weighed and volatile solvents were compensated before use. Working solutions were prepared by diluting stock solutions and derivatized.

\subsection{Carbonaceous materials}

Char, HA, and peat were used as carbonaceous materials in this study. Char was prepared by atmospheric pyrolysis according to the method of Braida et al. (2003). Willow-wood shavings were placed in a $15-\mathrm{cm}$ watch-glass-covered crucible and heated at $400{ }^{\circ} \mathrm{C}$ for $2 \mathrm{~h}$. The samples were then rinsed with ultrapure water. Peat used in this study was commercially available (Klasmann-Deilmann GmbH, Germany). HA was isolated from peat according to the International Humic Substances Society (IHSS) procedure as described in our previous work (Wen et al., 2007). Briefly, to each of six $250 \mathrm{ml}$ glass centrifuge bottles, $20 \mathrm{~g}$ of the peat soil was added, and each bottle was filled with $200 \mathrm{ml}$ of distilled water. The $\mathrm{pH}$ of the soil suspensions was then adjusted to $1-2$ with $1 \mathrm{M} \mathrm{HCl}$. After shaking for $1 \mathrm{~h}$, the suspensions were centrifuged (at $6555 \mathrm{rpm}, 30 \mathrm{~min}$ ) and the supernatants decanted. The solids were then neutralized by $1 \mathrm{M} \mathrm{NaOH}$ to $\mathrm{pH}$, and $200 \mathrm{ml}$ of $0.1 \mathrm{M} \mathrm{NaOH}$ was added to resuspend the solid under a $\mathrm{N}_{2}$ stream. The suspensions were immediately sealed, shaken overnight, and centrifuged. The supernatants were decanted, acidified with $6 \mathrm{M} \mathrm{HCl}$ to $\mathrm{pH} \mathrm{1,} \mathrm{and} \mathrm{allowed} \mathrm{to} \mathrm{sit} \mathrm{for} 24 \mathrm{~h}$ before $\mathrm{HA}$ and fulvic acid (FA) fractions were separated by centrifugation. The precipitated HA fraction was then redissolved in a minimum amount of $0.1 \mathrm{M} \mathrm{KOH}$ under $\mathrm{N}_{2}$, to which $\mathrm{KCl}$ was added to give approximately $0.3 \mathrm{M}$ for $\mathrm{K}^{+}$. The $\mathrm{HA}$ solution was again centrifuged to remove the suspended solids. This dissolution-precipitation procedure was repeated three times. The HA solution was then acidified and transferred to a dialysis bag having a molecular cutoff of $12,000-14,000 \mathrm{Da}$, it was dialyzed with distilled water until the test of $\mathrm{Cl}^{-}$in water with $\mathrm{AgNO}_{3}$ turned negative. The dialysis step also removed the residual FA in HA. The solid HA was obtained by freeze-drying.

The char, HA and peat obtained were pulverized in a mortar to pass through a $0.25 \mathrm{~mm}$ sieve, and stored in a glass vial at room temperature. The $\mathrm{pH}$ values are $7.53,2.87$ and 4.28 for char, HA and peat, respectively. The ash contents of all carbonaceous materials were lower than $10 \%$. The OC fractions were $45.3,51.3$ and $72.9 \%$ for char, HA and peat, respectively.

\subsection{Soils}

Three uncontaminated Chinese cultivated soils were collected from Jiangxi Province, South China (S1), Hebei Province, North China (S2), Beijing, North China (S3) in the year 2003. The soils were air-dried, ground, and passed through a $2-\mathrm{mm}$ sieve to remove stones, plant roots, and other large particles. Soil $\mathrm{pH}$ was measured in both distilled water and $0.01 \mathrm{~mol} / \mathrm{L} \mathrm{CaCl}_{2}$ solution, respectively, using a soil/ solution ratio of $1: 5(\mathrm{w}: \mathrm{v})$. Organic matter content was determined by the WalkleyBlack procedure (Nelson and Sommers, 1982). The uncontaminated soils were sterilized and spiked with PCP, stored for 4 years. Details of soil spiking and aging were described previously (Hu et al., 2005). Total concentrations of PCP in soils were determined. Char, HA and peat were mixed with soils separately at a carbonaceous material to soil ratio of $2.0 \%(\mathrm{w}: \mathrm{w})$. The amended soils were thoroughly mixed on a rotary shaker for $24 \mathrm{~h}$, and transferred into glass jars. The jars were sealed with screw caps fitted with Teflon liners and stored in the dark at $20 \pm 1{ }^{\circ} \mathrm{C}$ for either 7 days or 250 days prior to sequential extraction, desorption and earthworm uptake experiments. Soils without carbonaceous material amendment were used as control. Soil S2 without PCP spiking was used as blank. No detectable PCP was found in blank and earthworm incubated in blank. The field-contaminated soil was collected from Hubei Province (F) at the end of 2006, amended with carbonaceous materials and stored in parallel with the spiked soils. The characteristics of the soils and initial concentrations of PCP in the soils are shown in Table 1.

\subsection{Sequential extraction}

PCP in soils with and without amendments was subjected to a sequential extraction. The extractions were carried out in triplicate. Extraction details are described below.

\subsubsection{Step 1. $0.01 \mathrm{~mol} / \mathrm{L} \mathrm{CaCl}_{2}$ extraction}

Ten milliliter of $0.01 \mathrm{~mol} / \mathrm{L} \mathrm{CaCl}_{2} / 1.5 \mathrm{mmol} / \mathrm{L} \mathrm{NaN}_{3}$ aqueous solution was added to $1.0 \mathrm{~g}$ (dry weight) of soil in $50 \mathrm{ml}$ glass centrifuge tubes. The tubes were shaken for $24 \mathrm{~h}$ on a tumble shaker at $100 \mathrm{rpm}$ at $22 \pm 1^{\circ} \mathrm{C}$ (preliminary experiments showed apparent equilibrium was achieved within $24 \mathrm{~h}$ ), and then centrifuged at $4000 \mathrm{rpm}$ for $20 \mathrm{~min}$. The supernatant was carefully transferred to another clean glass centrifuge tube. Then $5 \mathrm{ml}$ was transferred to another clean centrifuge tube and adjust the $\mathrm{pH}$ to 4.0 . The acidic solution was extracted twice with $10 \mathrm{ml}$ hexane. The upper organic layers were collected and concentrated to $1 \mathrm{ml}$ under a gentle stream of $\mathrm{N}_{2}$, and then cleaned, derivatized and determined.

\subsubsection{Step 2. Butanol extraction}

The residue from step 1 was freeze dried and then $20 \mathrm{ml}$ of butanol was added. The tubes were covered, and the soil-butanol slurry was mixed strongly to break down the soil mass, after that the tubes were shaken for $24 \mathrm{~h}$ on a tumble shaker at $100 \mathrm{rpm}$ at $22 \pm 1{ }^{\circ} \mathrm{C}$ (preliminary experiments showed apparent equilibrium was achieved within $24 \mathrm{~h}$ ), then centrifuged at $4000 \mathrm{rpm}$ for $30 \mathrm{~min}$. The supernatant was carefully removed, concentrated to $1 \mathrm{ml}$, cleaned, derivatized, and determined.

\subsubsection{Step 3. DCM extraction}

The soil residue from step 2 was freeze dried, loosened using a clean stainless steel spatula, weighed, transferred to a filter paper package mixing with anhydrous sodium sulphate, and extracted with dichloromethane for $24 \mathrm{~h}$ using a Soxhlet apparatus. The extractants were concentrated to $1 \mathrm{ml}$, cleaned, derivatized and determined.

\subsection{XAD-2 assisted desorption experiment}

Desorption of PCP from soil S2 was conducted in triplicate by a modified XAD-2 shaken slurry desorption method of Northcott and Jones (2001).

Amberlite XAD-2 resin (Supelco, Bellefonte, PA), a macroreticular, polystyrene, nonionic bead, with particle size of 20-60 mesh, surface area of $300 \mathrm{~m}^{2} / \mathrm{g}$, wet density of $1.02 \mathrm{~g} / \mathrm{ml}$, and a pore diameter of $90 \mathrm{~nm}$, is applied to assist the desorption of PCP from Hebei soil. The resin was prepared by soaking in methanol (MeOH) to remove entrapped air and trace of residual monomeric compound and preservative reagents. After $24 \mathrm{~h}$ the $\mathrm{MeOH}$ was decanted and exchanged with a freshly prepared solution of $0.01 \mathrm{~mol} / \mathrm{L} \mathrm{CaCl}_{2}$ aqueous solution containing $100 \mathrm{mg} / \mathrm{L} \mathrm{NaN}_{3}$ which was

Table 1

Characteristics of soils studied.

\begin{tabular}{|c|c|c|c|c|c|c|c|c|}
\hline \multirow[t]{2}{*}{ Soils } & & \multirow[t]{2}{*}{ OC (\%) } & \multicolumn{2}{|l|}{$\mathrm{pH}$} & \multirow[t]{2}{*}{ PCP concentration $(\mu \mathrm{g} / \mathrm{g})$} & \multicolumn{3}{|c|}{ Particle size (\%) } \\
\hline & & & Water & $\mathrm{CaCl}_{2}$ & & Sand & Silt & Clay \\
\hline \multirow{3}{*}{ Lab-contaminated soils } & S1 & 0.893 & $6.01 \pm 0.04$ & $5.65 \pm 0.02$ & $0.79 \pm 0.01$ & 19.5 & 35.2 & 45.3 \\
\hline & S2 & 2.63 & $7.62 \pm 0.14$ & $7.15 \pm 0.06$ & $1.21 \pm 0.13$ & 13.7 & 59.0 & 27.3 \\
\hline & S3 & 0.783 & $8.16 \pm 0.03$ & $7.73 \pm 0.01$ & $7.19 \pm 0.60$ & 37.6 & 51.6 & 10.8 \\
\hline Field-contaminated soil & $\mathrm{F}$ & 2.12 & $7.79 \pm 0.01$ & $7.63 \pm 0.07$ & $2.44 \pm 0.28$ & 27.6 & 46.6 & 26.6 \\
\hline
\end{tabular}


used to inhibit bacteria activity. The aqueous solution was changed 10 times to ensure complete removal of $\mathrm{MeOH}$.

Soil samples of $0.25 \mathrm{~g}$ and $0.5 \mathrm{~g}$ wet XAD-2 resin were weighed directly into a glass centrifuge tubes $(50 \mathrm{ml})$ equipped with Teflon lined screw cap. Forty milliliters of $0.01 \mathrm{~mol} / \mathrm{L} \mathrm{CaCl}_{2}-100 \mathrm{mg} / \mathrm{L} \mathrm{NaN}_{3}$ solution was added. An aqueous solution of $0.01 \mathrm{~mol} / \mathrm{L} \mathrm{CaCl}_{2}$ was used to prevent the dispersion of soil clay particles, while $100 \mathrm{mg} / \mathrm{L} \mathrm{NaN}_{3}$ was included to prevent microbial growth. The tubes were sealed, placed on a tumble shaker at $100 \mathrm{rpm}$ at $22 \pm 1{ }^{\circ} \mathrm{C}$. Triplicate tubes were removed and analyzed. At each desorption time interval, $2.0 \mathrm{~g}$ of $\mathrm{K}_{2} \mathrm{CO}_{3}$ was added to promote phase separation. The tubes were resealed, vigorously shaken by hand to mix the contents. Then the tubes were stood vertically for $5 \mathrm{~min}$ to allow settling of the soilresin-water slurry, and centrifuged at $4000 \mathrm{rpm}$ for $20 \mathrm{~min}$ to separate the soil and resin. The resin was isolated, washed with $10 \mathrm{ml} 0.01 \mathrm{~mol} / \mathrm{L} \mathrm{CaCl}_{2}-100 \mathrm{mg} / \mathrm{L} \mathrm{NaN}_{3}$ solution to remove $\mathrm{K}_{2} \mathrm{CO}_{3}$. Then it was transferred into another glass tube, mixed with $2 \mathrm{~g}$ anhydrous $\mathrm{Na}_{2} \mathrm{SO}_{4}$. The PCP absorbed to XAD-2 resin was extracted by $5 \mathrm{ml}$ of hexane for 3 times. The extractant was concentrated to $1.0 \mathrm{ml}$ by rotary evaporation prior to analysis.

In order to make certain the XAD-2 resin extraction method, the sorption ability of XAD-2 resin under different $\mathrm{pH}$ condition (4.0, 6.0 and 8.0 ) was evaluated in our preliminary experiments. The results showed that XAD-2 could sorb $10 \mu \mathrm{g} / \mathrm{ml}$ PCP from $40 \mathrm{ml} 0.01 \mathrm{~mol} / 1 \mathrm{CaCl}_{2}$ solution under different $\mathrm{pH}$ effectively within $5 \mathrm{~min}$, with the recovery higher than $95 \%$. Mass balance was checked as the sum of PCP desorbed at each transfer time plus the residual PCP mass remaining in the soil. The recovery was $98 \pm 15 \%$ of the initial soil concentration.

Two-compartment first-order kinetic model (Northcott and Jones, 2001) was used to describe the desorption of PCP from Hebei soil. It is assumed that desorption of PCP from soil has two discrete, independent compartments, labile and resistant for PCP binding. Simultaneous first-order desorption for this system is expressed mathematically as

$\frac{q(t)}{q_{0}}=\Phi_{1} \exp \left(-k_{1} t\right)+\left(1-\Phi_{1}\right) \exp \left(-k_{2} t\right)$

where $q(t)$ is the solid-phase PCP concentration at a given time $t ; q_{0}$ is the initial solid-phase PCP concentration; $\Phi_{1}$ is the labile fraction of PCP; $k_{1}$ and $k_{2}$ are the apparent first-order rate constants for the labile and resistant fractions, respectively; $t$ is the desorption time.

\subsection{Earthworm uptake}

Earthworms (Eisenia fetida) were served to assess the bioavailability of the sorbed PCP to biological uptake. They were purchased from the Agricultural University of China (Beijing, China), with an average $0.50 \mathrm{~g}$ fresh weight each and $3.5-4.5 \mathrm{~cm}$ in length.

The uptake of PCP by earthworm in both amended and unamended soil samples was determined. Fourteen adult earthworms were transferred to moist (20\%) soil samples $(350 \mathrm{~g})$ in $500 \mathrm{ml}$ glass beaker, which was covered with aluminum foil with 2 holes per square centimeter to prevent earthworm escape and allow air exchange. The beakers were kept in the dark at $22 \pm 2{ }^{\circ} \mathrm{C}$. Four replicates were tested for each soil sample. After 30 days of exposure, the earthworms were removed from the glass beaker, washed with deionized water, transferred to wet filter paper in glass beaker in the dark to allow purging of gut contents. After $24 \mathrm{~h}$, they were rinsed with deionized water, wiped with filter paper, weighed, put into an aluminum foil and kept in $-20^{\circ} \mathrm{C}$ refrigerator before measurement. The bioaccumulation factors (BAFs) were obtained based on the following equation:

$\mathrm{BAF}=C_{\text {worm }} / C_{\text {soil }}$

where $C_{\text {worm }}$ is the concentration of PCP in earthworms on a wet-weight base (mg/ $\mathrm{kg}$ ) and $C_{\text {soil }}$ is the concentration of PCP in soil on a dry-weight base $(\mathrm{mg} / \mathrm{kg})$, which is considered constant, because the uptake of PCP by earthworms results in only a negligible reduction of their concentrations in soil.

\subsection{Long-term effect}

In order to test the long-term effect of carbonaceous material amendment, the fractionation and earthworm uptake tests in soil S2 were conducted after 250 days of aging. The procedures of fractionation and earthworm uptake tests were the same as those described in Sections 2.4 and 2.6.

\subsection{PCP quantification}

PCP in soils and earthworm was extracted by DCM using Soxhlet extraction. The soils were freeze dried prior to Soxhlet extraction. The frozen earthworms were ground with a mortar and pestle. Soil $(0.2 \mathrm{~g})$ or ground earthworm tissue $(0.1 \mathrm{~g})$ was mixed with ca. $10 \mathrm{~g}$ anhydrous $\mathrm{Na}_{2} \mathrm{SO}_{4}$ in paper extraction thimbles and then extracted with $80 \mathrm{ml}$ dichloromethane for $24 \mathrm{~h}$ at $10 \mathrm{~min} \mathrm{cycle}^{-1}$. The extractant was then concentrated to $2 \mathrm{ml}$ by rotary evaporator. To assure quality of the proposed analytical method, blank was analyzed in each analytical run. The blank values were determined by extracting an empty cellulose thimble by the same procedure as the real sample. No chromatographic peak of derivatized PCP was found in chromatograms of the blank. All the samples were cleaned using a column $(1 \mathrm{~cm}$ i.d. $\times 5 \mathrm{~cm})$. The column was prepared by packing silica gel (60-80 mesh), which was activated at $120^{\circ} \mathrm{C}$ for $2 \mathrm{~h}$, deactivated by a water to silica ratio $3: 100$ (w:w), and deposited in dichloromethane, covered by a $2 \mathrm{~cm}$ layer of anhydrous $\mathrm{Na}_{2} \mathrm{SO}_{4}$, and then washed with $60 \mathrm{ml}$ dichloromethane. The eluate was concentrated to $1 \mathrm{ml}$ by rotary evaporator prior to derivatization.

Acetic anhydride was used for derivatization of PCP. In brief, $10 \mathrm{ml}$ of $0.1 \mathrm{~mol} / \mathrm{L}$ $\mathrm{K}_{2} \mathrm{CO}_{3}, 10 \mu \mathrm{l}$ of the internal standard TBP $(10 \mathrm{mg} / \mathrm{L})$ were added sequentially. The solution was stirred for $10 \mathrm{~min}$, and then $0.5 \mathrm{ml}$ acetic anhydride was added. After stirring for $20 \mathrm{~min}, 9 \mathrm{ml}$ hexane was added. The tube was stirred and set for $10 \mathrm{~min}$ before analysis.

Gas chromatography (Agilent 6890N) equipped with an ${ }^{63} \mathrm{Ni}$ electric capture detector (ECD) (Hewlett-Packard 6890, USA) and an HP-5 capillary column (30$\mathrm{m} \times 0.32-\mathrm{mm}$-id $\times 0.25-\mu \mathrm{m})(\mathrm{J} \& \mathrm{~W}, \mathrm{USA})$ was used to determine the quantity of PCP in samples. The injector temperature was set at $250^{\circ} \mathrm{C}$; the detector temperature was $300^{\circ} \mathrm{C}$; the initial column temperature was $59^{\circ} \mathrm{C}$, programmed at $59^{\circ} \mathrm{C}$ for $1 \mathrm{~min}$, then from 59 to $180^{\circ} \mathrm{C}$ at $30^{\circ} \mathrm{C} / \mathrm{min}$, and maintained at the temperature for $3 \mathrm{~min}$, then from $180{ }^{\circ} \mathrm{C}$ to $185^{\circ} \mathrm{C}$ at $10{ }^{\circ} \mathrm{C} / \mathrm{min}$, and then from $185^{\circ} \mathrm{C}$ to $250^{\circ} \mathrm{C}$ at $30^{\circ} \mathrm{C} / \mathrm{min}$, with the final temperature maintained for $2 \mathrm{~min}$. The total analytical time was $12.7 \mathrm{~min}$. The recovery of the extraction-clean up-derivatization-determination process ranged from $83.2 \%$ to $92.0 \%$.

\subsection{Data analysis}

Statistical analyses were conducted with the software SPSS 11.5 for Windows (SPSS Inc. Chicago, USA). Parameter sets for Eq. (1) were optimized by nonlinear regression at $95 \%$ confidence. The values of soil pH, total concentrations of PCP in soil and fractions, and in earthworms are reported as mean \pm standard errors. Pairedsamples $t$-test analysis was performed to establish significant differences between treatments with and without carbonaceous amendments.

\section{Results and discussion}

\subsection{Effect of carbonaceous material amendment on soils $\mathrm{pH}$}

PCP is a hydrophobic weak organic acid ( $\mathrm{pKa}=4.75)$; therefore, it exists as either a protonated or a deprotonated species. When soil $\mathrm{pH}$ is below 2 more than $99 \%$ of total PCP is present as protonated species, whereas more than $95 \%$ of total PCP is present as deprotonated form when the $\mathrm{pH}$ is above 6 (Diaz-Flores et al., 2006). Stapleton et al. (Stapleton et al., 1994) found that sorption of PCP was affected by $\mathrm{pH}$ condition. Between $\mathrm{pH} 4$ and 8.5 , the sorption decreases by three times and the solubility increases 3 orders of magnitude as the dominant aqueous species change. Thus, effect of amendment on $\mathrm{pH}$ of the soils was conducted. Soil $\mathrm{pH}$ values determined in water are shown in Fig. 1. Amendment with HA resulted in 1.1, 1.2, 1.3 and $1.0 \mathrm{pH}$ unit decrease for $\mathrm{S} 1, \mathrm{~S} 2, \mathrm{~S} 3$ and $\mathrm{F}$ soils, respectively $(p<0.05)$, while amendment with peat led to significant soil $\mathrm{pH}$ decrease only for S3 and F soils $(p<0.05)$.

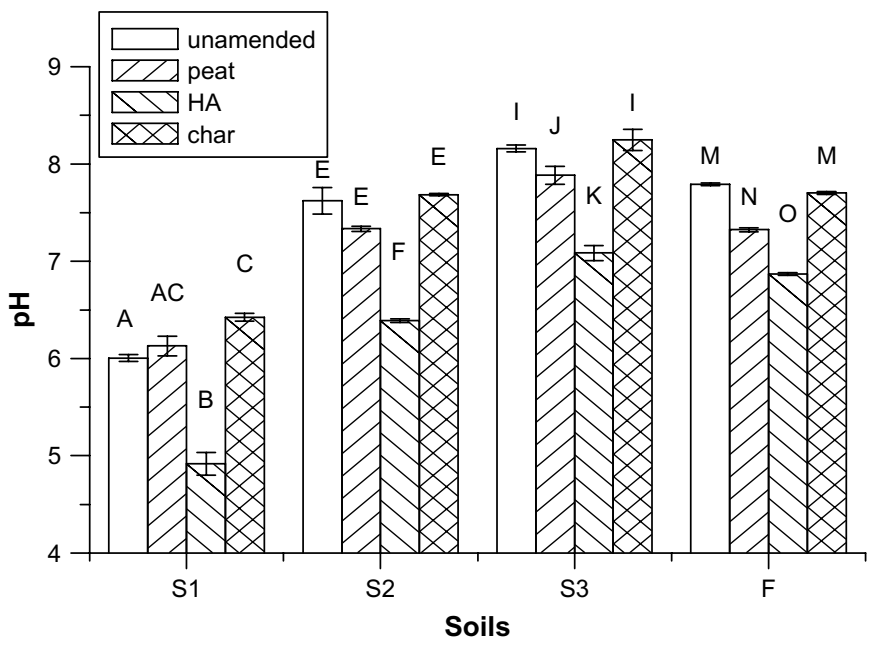

Fig. 1. $\mathrm{pH}$ of soils amended with carbonaceous materials. Error bars represent one standard deviation. Bars with same letter or letters imply no significant difference $(p<0.05)$. 
According to Stapleton's finding (Stapleton et al., 1994), PCP's protonated form is strongly hydrophobic with a low aqueous solubility. Therefore, it could be postulated that decrease of soil $\mathrm{pH}$ might result in partial conversion of $\mathrm{PCP}^{-}$into $\mathrm{PCP}^{0}$, thereby increasing sorption of PCP in soils. Char amendment significantly increased $\mathrm{pH}$ of soil S1 $(p<0.05)$, but did not change $\mathrm{pH}$ of S2, S3 and $\mathrm{F}$ soils. Similar tendency was observed for soil $\mathrm{pH}$ measured in $0.01 \mathrm{~mol} / \mathrm{L} \mathrm{CaCl}_{2}$ solution (data not shown).

\subsection{Fractionation of PCP in the soils amended by carbonaceous materials}

In order to evaluate the validity of the fractionation and determination performance, soils were subjected to the fractionation and subsequent determination of PCP before carbonaceous amendment. The relative standard deviation of PCP concentrations for six replicated determinations in $\mathrm{CaCl}_{2}, n$-butanol and DCM fractionations was in the range of $2.8-14.7 \%$. The sum of PCP in the three fractions was comparable with the total PCP contents obtained by Soxhlet extraction of soils, thereby showing the validity of the fractionation and determination performance (data not shown).

The fraction distribution of PCP differed significantly among various soils (Fig. 2). The extracted PCP by $0.01 \mathrm{~mol} / \mathrm{l} \mathrm{CaCl}_{2}$ aqueous solution for unamended S1, S2, S3 and F soils was 21.9, 23.5, 52.8, and $18.4 \%$ of total PCP contents in soils, respectively. After carbonaceous material amendment $\mathrm{CaCl}_{2}$ extractable PCP was significantly decreased for all soils studied ( $p<0.05$, Fig. 2 ). Lee et al. (1990) suggested that hydrophobic sorption of protonated PCP predominates at $\mathrm{pH}<7$, which could be predicted by solution $\mathrm{pH}$ and soil organic carbon content. At $\mathrm{pH}>7$, sorption of deprotonated $\mathrm{PCP}$ form $\left(\mathrm{PCP}^{-}\right)$and the formation and sorption of neutral ion pairs [e.g., metal cation $\left(\mathrm{M}^{+}\right)+\left(\mathrm{PCP}^{-}\right)=\mathrm{MPCP}^{0}$ ] was considered. After HA amendment, $\mathrm{pH}$ value of all the soils was lower than 7.0. In this case, SOM and added HA play important roles in retention of PCP.

Peat is an inexpensive and easily available adsorbent. It is used extensively with very good results as plant growth media (Herrera et al., 2008). Tanjore and Viraraghavan (1997) applied peat for removal of PCP from acidic aqueous media. In this study, $\mathrm{CaCl}_{2}$ extractable PCP was reduced to $8.30,16.2,39.2$ and $11.5 \%$ of total PCP for S1, S2, S3 and F soils amended with HA, respectively. However, no significant change of DCM extractable PCP was found after peat amendment (Fig. 2).

Char is one of the high surface area carbonaceous materials. It has high sorption capacity not only for HOCs (Cornelissen et al., 2005), but also for anion (Daifullah et al., 2007). Mukherjee et al. (2007) used char to sorb phenolic compounds from water over a wide $\mathrm{pH}$ range. Among carbonaceous material amendments studied, the most significant changes of PCP distribution patterns were found by char amendment. After char addition, $\mathrm{CaCl}_{2}$ extractable PCP decreased to 10.1, 15.0, 37.0 and $2.14 \%$ of total, while the DCM extractable PCP increased significantly $(p<0.05)$ to 29.6, $27.1,22.2$ and $45.0 \%$ of total PCP in S1, S2, S3 and F soils, respectively (Fig. 2).

It is assumed that extraction with $0.01 \mathrm{~mol} / 1 \mathrm{CaCl}_{2}$ removes polar PCP and soluble neutral PCP from soil. $\mathrm{CaCl}_{2}$ extractable amount of organic pollutants was regarded as closely related with leaching and bioavailability to organisms (Bergknut et al., 2007), though results obtained by Kelsey et al. (1997) showed that water extraction would cause underestimation of bioavailability. Butanol is suggested to remove the weakly associated fraction of HOCs in soil in a single extraction (White et al., 1999). Liste and Alexander (2002) and Kelsey et al. (1997) proposed that butanol extraction was a feasible method for earthworm accumulation and bacterial mineralization prediction. While several studies have shown that
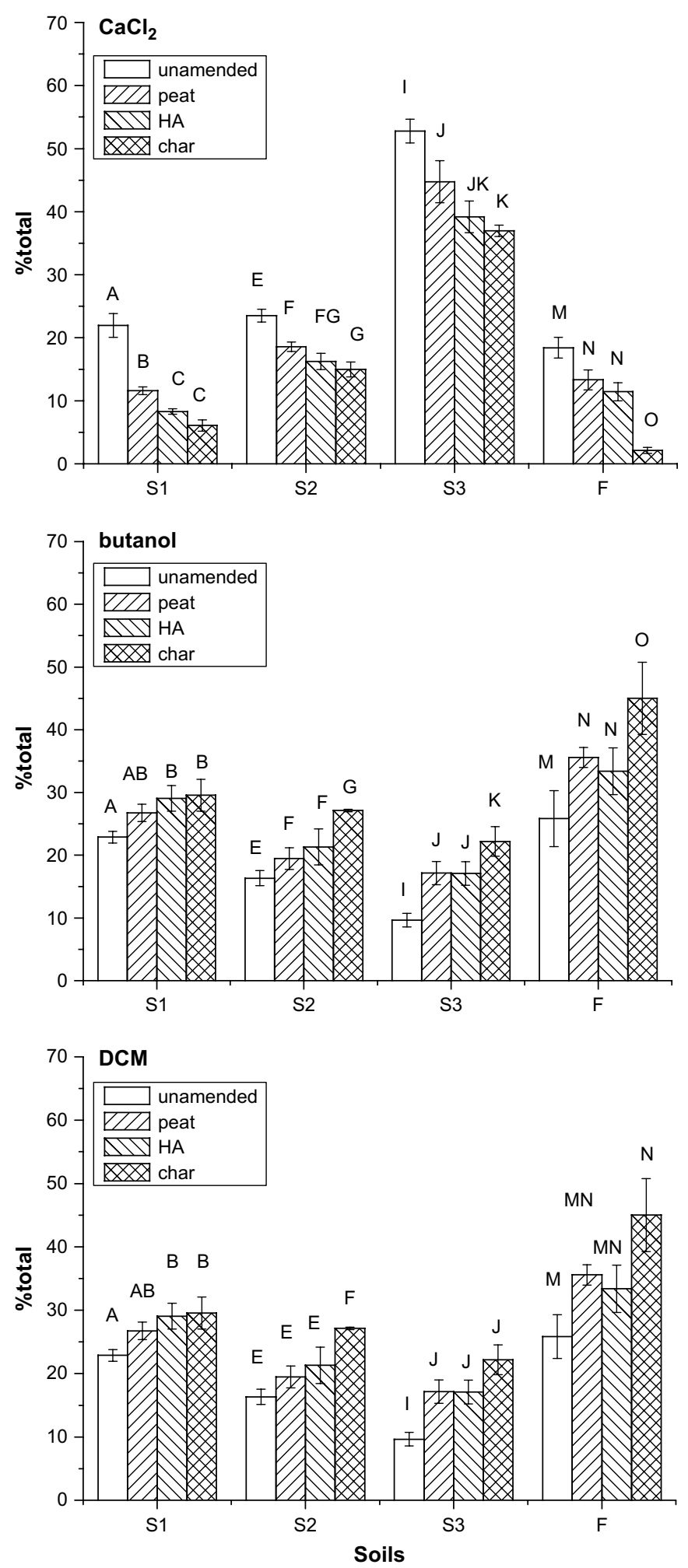

Fig. 2. Extractable fractions of $P C P$ in soils amended with carbonaceous materials after aging of 7 days using $\mathrm{CaCl}_{2}, \mathrm{BuOH}$ and DCM as extractants. Error bars represent one standard deviation. Bars with same letter or letters imply no significant difference $(p<0.05)$.

butanol is an exhaustive extractant and largely overestimate microbial mineralization (Reid et al., 2000; Northcott and Jones, 2003). The butanol extractable PCP from unamended S1, S2, S3 and F soils was 55.2, 60.6, 37.6, and 50.9\% of total PCP in soil, respectively (Fig. 2). After char, HA and peat amendments, butanol 
extractability was not significantly changed for all soils except that butanol extractable PCP increased for soil S1 amended with HA.

Harsh extractants, such as DCM, are generally used to quantify the total amount of HOCs in soil by a single extraction (Macleod and Semple, 2003), which overestimate the contaminant fraction available to soil biota (Hatzinger and Alexander, 1995; Reid et al., 2000). In this study, DCM was used as a final sequential extractant after $\mathrm{CaCl}_{2}$ and $n$-butanol extractions. It is obvious that after char amendment, PCP extracted by DCM increased $(p<0.05)$ for all soils (Fig. 2). The decrease of $\mathrm{CaCl}_{2}$ extractable and increase of DCM extractable PCP indicated that a fraction of PCP became more strongly associated with soil after carbonaceous materials addition.

\subsection{Effect of carbonaceous material amendments on PCP desorption kinetics}

PCP desorption from soil S2 is shown in Fig. 3. The lines obtained by two-compartment first order kinetics fits are included in the graphs. Corresponding desorption rate parameters with $95 \%$ confidence intervals are listed in Table 2. The first-order kinetic model provides an acceptable description of PCP desorption from soil with and without amendment, with all $R^{2}$ values higher than 0.980 . Amendment with char significantly decreased the labile fraction of PCP ( $\Phi_{1}$ value) from 0.342 to 0.196 , and the labile and resistant desorption rate constants were also decreased from 19.1 to $5.86 \mathrm{~d}^{-1}\left(k_{1}\right)$, and from 0.113 to $0.012 \mathrm{~d}^{-1}\left(k_{2}\right)$, respectively $(p<0.05)$. Similar decreases of $k_{1}$ and $k_{2}$ values were observed for HA and peat amendments, though $\Phi_{1}$ values were not significantly changed as compared to soil without amendment. Such decreases suggested that PCP binding shifted from easy desorption to relatively difficult desorption sites as a result of carbonaceous material addition. This is in conformity with the observations to indicate the impact of carbonaceous material amendments on PCP leaching ability and bioaccumulation by earthworms.

The above results are strongly supported by current knowledge that SOM controls the fate and transport of organic contaminants in soils. Results obtained by van Noort et al. (2003) showed that the rapid desorption rate of HOCs was correlated natively with SOM content. Accordingly, amendments with carbonaceous materials would increase SOM content, resulting in lower desorption rate of labile fraction of PCP. Johnson et al. (2001) found that rates and extents of desorption of HOCs are strong functions of the type of natural organic matter that soil contains. Pignatello and Xing

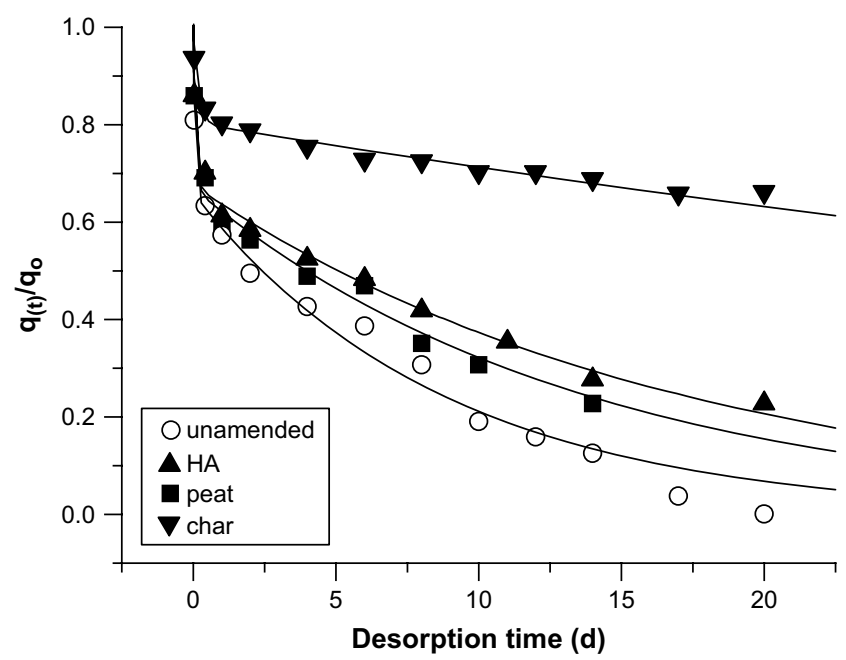

Fig. 3. PCP desorption from soil S2 amended with carbonaceous materials (lines fit Eq (1)).
Table 2

Desorption rate parameters for the biphasic first-order model with $95 \%$ confidence intervals of PCP from soil S2.

\begin{tabular}{lllllll}
\hline Soil & $\Phi_{1}$ & $k_{1}\left(\mathrm{~d}^{-1}\right)$ & $k_{2}\left(\mathrm{~d}^{-1}\right)$ & $R^{2}$ & $N^{\mathrm{a}}$ & MWSE $^{\mathrm{b}}$ \\
\hline Unamended & $0.342 \pm 0.025$ & $19.1 \pm 0.8$ & $0.113 \pm 0.009$ & 0.983 & 36 & 0.0087 \\
Char & $0.196 \pm 0.008$ & $5.86 \pm 0.06$ & $0.012 \pm 0.001$ & 0.986 & 36 & 0.0014 \\
HA & $0.324 \pm 0.014$ & $12.9 \pm 1.2$ & $0.058 \pm 0.003$ & 0.990 & 36 & 0.032 \\
Peat & $0.331 \pm 0.020$ & $12.5 \pm 0.8$ & $0.073 \pm 0.006$ & 0.985 & 36 & 0.020 \\
\hline
\end{tabular}

a $N$ : number of data point.

b MWSE: mean weight square error, calculated as $1 / v \Sigma\left[\left(q_{\text {measured }}-q_{\text {model }}\right)^{2} /\right.$ $q^{2}$ measured], $v=N-3$.

(1996), and Huang and Weber (1998) hypothesized that rigid parts of the organic matter matrix could be responsible for slow desorption of HOCs. Cornelissen et al. (2005) suggested that the "rigid" or "glassy" parts of SOM is in fact the same as the carbonaceous geosorbents (CG), such as black carbon, char, and kerogen, and thus that sorption to CG probably causes slow desorption. Therefore, addition of char would cause sorption of PCP from SOM to char, thereby resulting in the most pronounced slow desorption. Moreover, char was also regarded as an ideal sorbents for anion (Daifullah et al., 2007), thus it could immobilize deprotonated PCP.

\subsection{PCP bioavailability to earthworms in soils}

During the accumulation experiments, no mortality was observed. The average weight of earthworms decreased by $12-22 \%$, but no significant weight difference was found for those in soils with and without amendment (data not shown). It is evident from the data presented in Fig. 4 that the bioavailability of PCP to earthworms in char amended soils decreased most significantly $(p<0.05)$, more specifically, values of BAF decreased by factors of 4.0-26.1. Similarly, for HA amended soils, significant reductions of BAF were found for all soils studied except soil S3. For peat amendment, the average BAF values were lower than those without amendment. However, significant reduction $(p<0.05)$ of BAF was only found for soil S2. These results suggested that carbonaceous material amendment reduced PCP bioavailability quickly. Among the amendments described in this study char appeared to be the most promising one. The above results implied that PCP bioavailability is dependent on the properties of soils and the amendments.

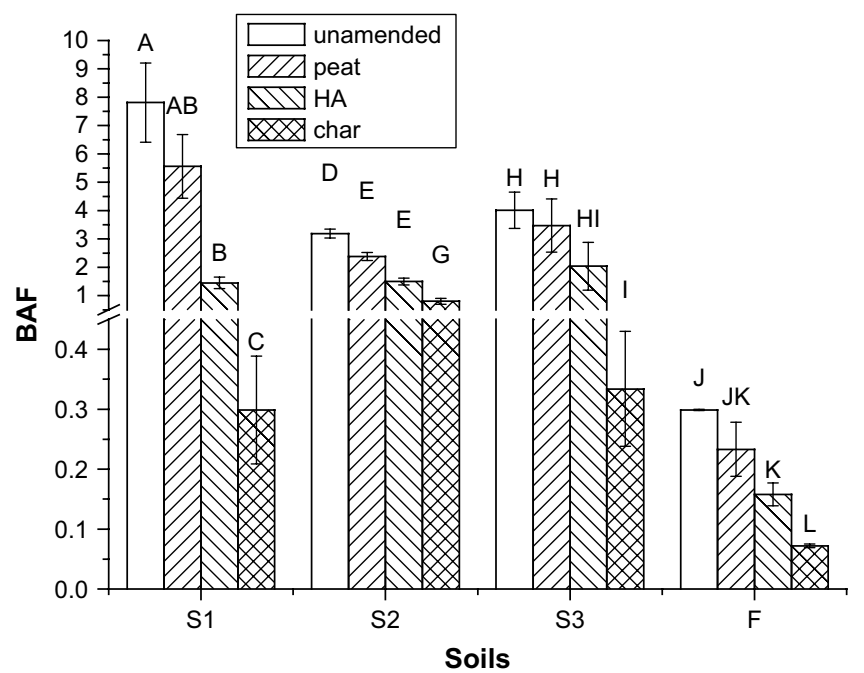

Fig. 4. Bioaccumulation factors (BAFs) for PCP present in soils amended with carbonaceous materials. Error bars represent one standard deviation. Bars with same letter or letters imply no significant difference $(p<0.05)$. 


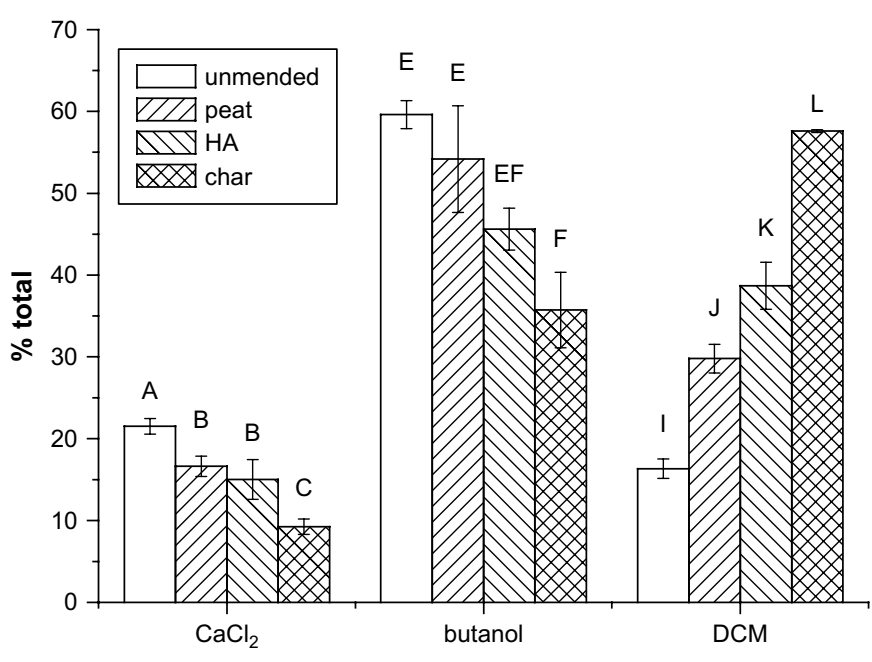

Fig. 5. Extractable fractions of PCP in soil S2 amended with carbonaceous materials for aging of 250 days using $\mathrm{CaCl}_{2}$, butanol and DCM as extractants. Error bars represent one standard deviation. Bars with same letter or letters imply no significant difference $(p<0.05)$.

\subsection{Long-term effect}

When the aging time increased to 250 days, total PCP concentration remained unchanged in soil S2, which showed the negligible biodegradation and volatilization during the incubation. No significant difference $(p>0.05)$ of soil $\mathrm{pH}$ was found when compared with those of 7 days incubation.

A comparison of PCP fractionation of 250-day aging treatment (Fig. 5) with that of control indicates that the $\mathrm{CaCl}_{2}$ extractable PCP decreased significantly $(p<0.05)$ for all amendments. The butanol extractability decreased significantly $(p<0.05)$ for char and HA amendments, but not for peat amendment. An obvious $(p<0.05)$ increase of DCM extractable PCP was found for all amendments. The different PCP fractionation distribution patterns revealed tighter PCP binding with increasing aging time. The average BAF values of $250-$ day aging were $0.78,0.60$ and 2.29 for char, HA and peat amendments, respectively, which were significantly lower than those of control (3.98) $(p<0.05)$. Results obtained from this experiment demonstrated that the PCP immobilization effect by char, HA and peat amendments is endurable and enhanced as time goes by.

\section{Environmental implication}

The traditional commonly applied amendments, such as char, HA and peat, are commercially available and cost-effective. As soil amendments have a long history, the benefit of char, HA and peat amendment to soil, soil microbes and plants had been demonstrated extensively under greenhouse and field conditions (Mbagwu and Piccolo, 1989; Govindasmy and Chandrasekaran, 1992; Koelmans et al., 2006; Herrera et al., 2008). Dercová et al. (2006) demonstrated that organic amendments, such as sewage sludge or organomineral complex have the advantages of retardation of contaminant release, and enhancement of contaminant biodegradation. Results of Zhang et al. (2005) showed that biodegradation might be nutritionally simulated for severely contaminated soils in the presence of char, but pollutants would remain highly persistent in the soils due to their increased sorption as a result of char amendment. Results of the present study suggested that soil amended with various types of carbonaceous materials provides a potential strategy for in situ environmental remediation, restoration, and stabilization applications. Appropriate selection of amendment materials is a key to realize the remediation potential. Different kinds of organic amendments described here and other alternatives provide a wide choice. Moreover, char, HA and peat are able to immobilize heavy metals in soil effectively (Pichtel and Bradway, 2008; Chen et al., 2006; Clemente and Bernal, 2006). Therefore, it is reasonable to regard them as a promising amendment technology, which may simultaneously stabilize heavy metals and organic pollutants in soil.

\section{Acknowledgements}

This work was funded by the National Natural Science Foundation of China (grant number 40730740, 20621703).

\section{References}

Bergknut, M., Sehlin, E., Lundstedt, S., Andersson, P.L., Haglund, P., Tysklind, M., 2007. Comparison of techniques for estimating PAH bioavailability: uptake in Eisenia fetida, passive samplers and leaching using various solvents and additives. Environmental Pollution 145, 154-160.

Boopathy, R., 2000. Factors limiting bioremediation technologies. Bioresource Technology 74, 63-67.

Boyd, S.A., Mikesell, M.D., Lee, J., 1989. Chlorophenols in Soil. Soil Science Society of America, Madison.

Braida, W.J., Pignatello, J.J., Lu, Y.F., Ravikovitch, P.I., Neimark, A.V., Xing, B.S., 2003. Sorption hysteresis of benzene in charcoal particles. Environmental Science \& Technology 37, 409-417.

Chen, B., Zhu, L., Zhu, J., Xing, B., 2005. Configurations of the bentonite-sorbed myristylpyridinium cation and their influences on the uptake of organic compounds. Environmental Science \& Technology 39, 6093-6100.

Chen, S.B., Zhu, Y.G., Ma, Y.B., McKay, G., 2006. Effect of bone char application on Pb bioavailability in a Pb-contaminated soil. Environmental Pollution 139, 433-439.

Cho, Y.-M., Smithenry, D.W., Ghosh, U., Kennedy, A.J., Millward, R.N., Bridges, T.S., Luthy, R.G., 2007. Field methods for amending marine sediment with activated carbon and assessing treatment effectiveness. Marine Environmental Research 64, 541-555.

Clemente, R., Bernal, M.P., 2006. Fractionation of heavy metals and distribution of organic carbon in two contaminated soils amended with humic acids. Chemosphere 64, 1264-1273.

Conte, P., Agretto, A., Spaccini, R., Piccolo, A., 2005. Soil remediation: humic acids as natural surfactants in the washings of highly contaminated soils. Environmental Pollution 135, 515-522.

Cornelissen, G., Gustafsson, Ö., Bucheli, T.D., Jonker, M.T.O., Koelmans, A.A., van Noort, P.C.M., 2005. Extensive sorption of organic compounds to black carbon, coal, and kerogen in sediments and soils: mechanisms and consequences for distribution, bioaccumulation, and biodegradation. Environmental Science \& Technology 39, 6881-6895.

Daifullah, A.A.M., Yakout, S.M., Elreefy, S.A., 2007. Adsorption of fluoride in aqueous solutions using $\mathrm{KMnO}_{4}$-modified activated carbon derived from steam pyrolysis of rice straw. Journal of Hazardous Materials 147, 633-643.

Davies, N.A., Edwards, P.A., Lawrence, M.A.M., Taylor, M.G., Simkiss, K., 1999. Influence of particle surfaces on the bioavailability to different species of 2,4dichlorophenol and pentachlorophenol. Environmental Science \& Technology 33, 2465-2468.

Dercová, K., Sejaková, Z., Skokánová, M., Baranciková, G., Makovniková, J., 2006. Potential use of organomineral complex (OMC) for bioremediation of pentachlorophenol (PCP) in soil. International Biodeterioration \& Biodegradation 58 , 248-253.

Diaz-Flores, P.E., Leyva-Ramos, R., Guerrero-Coronado, R.M., Mendoza-Barron, J., 2006. Adsorption of pentachlorophenol from aqueous solution onto activated carbon fiber. Industrial \& Engineering Chemistry Research 45, 330-336.

Govindasmy, R., Chandrasekaran, S., 1992. Effect of humic acids on the growth, yield and nutrient content of sugarcane. The Science of the Total Environment 117$118,575-581$.

Hatzinger, P.B., Alexander, M., 1995. Effect of aging of chemicals in soil on their biodegradability and extractability. Environmental Science \& Technology 29, 537-545.

Herrera, F., Castillo, J.E., Chica, A.F., Lopez Bellido, L., 2008. Use of municipal solid waste compost (MSWC) as a growing medium in the nursery production of tomato plants. Bioresource Technology 99, 287-296.

Hu, X.Y., Wen, B., Shan, X.Q., Zhang, S.Z., 2005. Bioavailability of pentachlorophenol to earthworms (Eisenia fetida) in artificially contaminated soils. Journal of Environmental Science and Health, Part A 40, 1905-1916.

Huang, W.L., Weber, W.J., 1998. A distributed reactivity model for sorption by soils and sediments. 11. Slow concentration dependent sorption rates. Environmental Science \& Technology 32, 3549-3555.

Johnson, M.D., Keinath, T.M., Weber, W.J., 2001. A distributed reactivity model for sorption by soils and sediments. 14. Characterization and modeling of phenanthrene desorption rates. Environmental Science \& Technology 35, 1688-1695.

Kelsey, J.W., Kottler, B.D., Alexander, M., 1997. Selective chemical extractants to predict bioavailability of soil-aged organic chemicals. Environmental Science \& Technology 31, 214-217. 
974

B. Wen et al. / Environmental Pollution 157 (2009) 968-974

Koelmans, A.A., Jonker, M.T.O., Cornelissen, G., Bucheli, T.D., van Mort, P.C.M., Gustafsson, Ö., 2006. Black carbon: the reverse of its dark side. Chemosphere 63, 365-377.

Lee, L.S., Roo, P.S.C., Nkedi-Kizza, P., Delfino, J.J., 1990. Influence of solvent and sorbent characteristics on distribution of pentachlorophenol in octanol-water and soil-water systems. Environmental Science \& Technology 24, 654-661.

Lister, H.-H., Alexander, M., 2002. Butanol extraction to predict bioavailability of PAH in soil. Chemosphere 46, 1011-1017.

Macleod, C.J.A., Semple, K.T., 2003. Sequential extraction of low concentrations of pyrene and formation of non-extractable residues in sterile and non-sterile soils. Soil Biology and Biochemistry 35, 1443-1450.

Mbagwu, J.S.C., Piccolo, A., 1989. Changes in soil aggregate stability induced by amendment with humic substances. Soil Technology 2, 49-57.

Millward, R.N., Bridges, T.S., Gosh, U., Zimmerman, J.R., Luthy, R.G., 2005. Addition of activated carbon to sediments to reduce PCB bioaccumulation by a polychaste (Neanthes arenaceodentata) and an amphipod (Leptocheirus plumulosus). Environmental Science \& Technology 39, 2880-2887.

Mukherjee, S., Kumar, S., Mira, A.K., Fan, M.H., 2007. Removal of phenols from water environment by activated carbon, bagasse ash and wood charcoal. Chemical Engineering Journal 129, 133-142.

Nelson, D.W., Summers, L.E., 1982. Methods of soil analysis: part 2. In: Page, A.L. (Ed.), Total Carbon, Organic Carbon and Organic Matter, second ed. ASA and SSSA, Madison, WI, pp. 539-579.

Northcott, G.L., Jones, K.C., 2001. Partitioning, extractability, and formation of nonextractable $\mathrm{PAH}$ residues in soil. 2. Effects on compound dissolution behavior. Environmental Science \& Technology 35, 1111-1117.

Northcott, G.L., Jones, K.C., 2003. Validation of procedures to quantify nonextractable polycyclic aromatic hydrocarbon residues in soil. Journal of Environmental Quality 32, 571-582.

van Mort, P.C.M., Cornelissen, G., ten Hulscher, T.E.M., Vrind, B.A., Rigterink, H., Belfroid, A., 2003. Slow and very slow desorption of organic compounds from sediment: influence of sorbate planarity. Water Research 37, 2317-2322.

Pichtel, J., Broadway, D.J., 2008. Conventional crops and organic amendments for $\mathrm{Pb}$ $\mathrm{Cd}$ and $\mathrm{Zn}$ treatment at a severely contaminated site. Bioresource Technology 99, 1242-1251.
Pignatello, J.J., King, B.S., 1996. Mechanisms of slow sorption of organic chemicals to natural particles. Environmental Science \& Technology 30, 1-11.

Reid, B.J., Stokes, J.D., Jones, K.C., Semple, K.T., 2000. Nonexhaustive cyclodextrinbased extraction technique for the evaluation of PAH bioavailability. Environmental Science \& Technology 34, 3174-3179.

Skrbic, B., Durisic-Mladenovic, N., 2007. Principal component analysis for soil contamination with organochlorine compounds. Chemosphere 68, 2144-2152.

Stapleton, M.G., Sparks, D.L., Dentel, S.K., 1994. Sorption of pentachlorphenol to HDTMA-clay as a function of ionic-strength and $\mathrm{pH}$. Environmental Science \& Technology 28, 2330-2335.

Tang, J., Petersen, E.J., Huang, Q., Weber Jr., W.J., 2007. Development of engineered natural organic sorbents for environmental applications: 3. Reducing $\mathrm{PAH}$ mobility and bioavailability in contaminated soil and sediment systems. Environmental Science \& Technology 41, 2901-2907.

Tang, J., Weber, W.J., 2006. Development of engineered natural organic sorbents for environmental applications. 2. Sorption characteristics and capacities with respect to phenanthrene. Environmental Science \& Technology 40, 1657-1663.

Tanjore, S., Viraraghavan, T., 1997. Effect of oxygen on the adsorption of pintachlorophenol by peat from water. Water Air and Soil Pollution 100, 151-162.

Weber, W.J., Tang, J., Huang, Q., 2006. Development of engineered natural organic sorbents for environmental applications. 1. Materials, approaches, and characterizations. Environmental Science \& Technology 40, 1650-1656.

Wen, B., Zhang, J.J., Zhang, S.Z., Shan, X.Q., Khan, S.U., King, B.S., 2007. Phenanthrene sorption to soil humic acid and different humin fractions. Environmental Science \& Technology 41, 3165-3171.

White, J.C., Hunter, M., Nam, K.P., Pignatello, J.J., Alexander, M., 1999. Correlation between biological and physical availabilities of phenanthrene in soils and soil humin in aging experiments. Environmental Toxicology and Chemistry 18, 1720-1727.

Chang, P., Sheng, G., Fens, Y., Miller, D., 2005. Role of wheat-residue-derived char in the biodegradation of benzonitrile in soil: nutritional stimulation versus adsorptive inhibition. Environmental Science \& Technology 39, 5442-5448.

Zimmerman, J.R., Gosh, U., Millward, R.N., Bridges, T.S., Lathy, R.G., 2004. Addition of carbon sorbents to reduce PCB and PAH bioavailability in marine sediments: physicochemical tests. Environmental Science \& Technology 38, 5458-5464. 